Recebido em 02/2019. Aceito para publicação em 08/2019.

\title{
UNIDADE DE TERAPIA INTENSIVA PEDIÁTRICA: VISÃO DA CRIANÇA SOBRE O PROCESSO DE INTERNAÇÃO
}

\section{PEDIATRIC INTENSIVE CARE UNIT: CHILD VIEW ON THE HOSPITALIZATION PROCESS}

\author{
Carolina Marchi Guerra ${ }^{1}$ \\ Fabíola Hermes Chesani² \\ Carina Nunes Bossardi ${ }^{3}$
}

Resumo: A internação hospitalar na infância é um acontecimento estressante, pois afasta a criança da rotina familiar e a insere em meio desconhecido, onde sua segurança é frequentemente ameaçada. $O$ presente artigo tem como objetivo conhecer a visão da criança sobre o processo de internação na Unidade de Terapia Intensiva Pediátrica. Estudo descritivo e exploratório com abordagem qualitativa, desenvolvido com sete crianças escolares de 7 a 12 anos. A técnica de coleta de dados foi a entrevista semiestruturada com questões sobre o motivo da internação e conhecimento sobre a Unidade de Terapia Intensiva Pediátrica. Os depoimentos foram analisados utilizando-se a Técnica de Análise de Conteúdo. Após análise das entrevistas realizadas, surgiram as seguintes categorias: conhecimento sobre o motivo de estar no hospital e conhecimento sobre o estar internado na UTI. É possível observar que a criança não faz rodeios, explica sucintamente o motivo de sua internação, é racional e direta. Sua resposta pode ter sido influenciada pelo que seus pais ou outras pessoas com as quais teve contato durante a internação disseram, mas ela tira suas próprias conclusões, formula seu diagnóstico e justifica sua internação. A internação hospitalar e principalmente a admissão da criança na Unidade de Terapia Intensiva Pediátrica são momentos de muita ansiedade e angústia vividos pela própria criança, pelos pais e familiares. De maneira geral, as crianças sabem o que está acontecendo em seus organismos, o porquê de estarem doentes e também compreendem a necessidade da internação para seu total restabelecimento.

Palavras-chave: Criança; hospitalização; unidade de terapia intensiva pediátrica.

Abstract: Hospital internment in childhood is a stressful event because it takes the child away from the family routine and inserts them in an unknown environment, where their own security is often threatened. This article aims to know the view of children about their internment in the Pediatric Intensive Care Unit. Descriptive and exploratory study with a qualitative approach, developed with seven school children between 7 and 12 years old. The data collection technique was a semi-structured interview with questions about the reason of hospitalization and knowledge about the Pediatric Intensive Care Unit. The testimonials were analyzed by the content analysis technique. After the analysis of the interviews, the following categories emerged: knowledge about the reason of being in the hospital and knowledge about the hospitalization in the Pediatric Intensive Care Unit. It is possible to observe that the children are straightforward, they explain succinctly the reason of hospitalization. Children are rational and direct. The answer could have been influenced by what their parents or other people with whom they had contact told them during the hospitalization, but children draw their own conclusions, formulate their diagnosis and justify their hospitalization. The hospital internment and mainly the admission of children in the Pediatric Intensive Care Unit are moments of great anxiety and anguish lived by the children themselves, by the parents and relatives.

\footnotetext{
${ }^{1}$ Mestre, Professora do Curso de Medicina, Universidade do Vale do Itajaí, Brasil. E-mail: camarchi@univali.br.

2 Doutora, Professora do Mestrado em Saúde e Gestão do Trabalho e do Curso de Fisioterapia, Universidade do Vale do Itajaí, Brasil. E-mail: fabiola.chesani@univali.br.

${ }^{3}$ Doutora, Professora do Mestrado em Saúde e Gestão do Trabalho e do Curso de Psicologia, Universidade do Vale do Itajaí, Brasil. E-mail: carinabossardi@univali.br.
} 
In general, the children know very well what is happening with their bodies, the reason why they are sick, and they also understand the need of hospitalization for their total restoration.

Keywords: Children; hospitalization; pediatric intensive care unit.

\section{INTRODUÇÃO}

A internação hospitalar é vista como um acontecimento perturbador independente da faixa etária. As experiências de adoecimento e internação hospitalar exigem que 0 indivíduo tenha de lidar com demandas que ultrapassam sua própria capacidade de adaptação. Na infância, isso fica muito mais evidente pois trata-se de uma experiência não esperada e que se cerca de muitas fantasias e medos, principalmente quando se trata da primeira vez que este evento ocorre (DOCA; COSTA JÚNIOR, 2007; COUTINHO; LIMA; BASTOS, 2016).

A experiência da internação hospitalar na infância, devido às suas características e rotinas muitas vezes rígidas e inflexíveis, pode ocasionar sentimentos negativos e afeta sensivelmente o estado emocional da criança hospitalizada, levandoa ao medo e a altas taxas de estresse. Isso acontece porque é nesse momento que ocorre a separação dos seus objetos que representam segurança e afeto, além da ausência dos pais e familiares que é percebida pela criança como um abandono por parte de seus entes queridos (XAVIER et al., 2013; SIMIONI et al., 2017).

É praticamente impossível passar por uma experiência como a internação em UTI e não se abalar, ou se impressionar com o que ocorreu. Isso acontece com todas as pessoas, e é especialmente mais perturbador quando se trata de crianças, podendo acarretar diversos traumas pela incapacidade destas em compreender a natureza de tais acontecimentos (QUIRINO; COLLET; NEVES, 2010).

Durante a internação, a criança é exposta a inúmeros procedimentos, invasivos ou não, e entrega-se à equipe, confiando nos seus cuidados. Tudo isso acontece em um ambiente desconhecido distante do seu cotidiano familiar, do brincar e dos estudos, e ainda, os procedimentos são realizados por pessoas estranhas, sem vínculo com a criança (CALVETTI; SILVA; GAUER, 2008).

Nas instituições pediátricas, ainda é comum a crença de que a criança não possui maturidade suficiente para compreender o processo de doença e hospitalização e com isso, os tratamentos são realizados, na maioria das vezes, a contragosto da família e das próprias crianças. Comumente algumas famílias querem evitar que as informações sobre a internação hospitalar, seus procedimentos e tratamentos, cheguem até a criança porque acreditam que isso possa causar efeitos indesejáveis. É importante ressaltar o componente emocional que determina diferenças entre crianças da mesma faixa etária e de desenvolvimento, mas também diferenças de nível de significação expressas pela mesma criança em situações diferentes (BARROS, 2003; MENEZES, 2010).

A maneira como o ser humano se relaciona com doença e hospitalização vem 
sendo modificada nos últimos anos graças ao avanço exponencial da tecnologia em saúde. O processo de doença e internação hospitalar em si próprio ou em algum familiar é gerador de adaptações e mudanças. Quando se trata de internação de uma criança em Unidade de Terapia Intensiva Pediátrica (UTIP), as emoções podem ser mais intensas (GEQUELIN et al, 2014).

As Unidades de Terapia Intensivas são ambientes complexos, que movimentam toda a infraestrutura hospitalar e serviços de apoio, tem rotina própria e diversos estressores - físicos, ambientais, psicológicos e sociais. Elas possibilitam a sobrevivência e o restabelecimento da saúde de uma pessoa criticamente doente, mas também se configuram em ambientes estressantes, de isolamento, ansiedade e de hiperestimulação sensorial. A quantidade de aparelhos e alarmes presentes na UTIP, torna-a um ambiente um tanto assustador para uma criança (MORAIS; COSTA, 2009; GEQUELIN et al, 2014).

Para as crianças, a internação hospitalar, além da exposição a procedimentos invasivos e de afastá-la de sua casa, escola, amigos e familiares, interfere diretamente em seu desenvolvimento. As crianças são mais sensíveis ao processo de hospitalização, precisam se adaptar rapidamente às mudanças em seu cotidiano, tendo que lidar com pessoas estranhas com as quais não tem intimidade, em um lugar hostil e que impõe uma rotina rígida (COUTINHO; LIMA; BASTOS, 2016).

O ambiente hospitalar é entendido pela criança como um local potencialmente ameaçador e perigoso, pois lá são realizados procedimentos invasivos e dolorosos. A internação hospitalar na infância pode ser potencialmente traumática, pois promove o afastamento dos entes queridos, dos brinquedos e das brincadeiras além do isolamento da criança e da separação de seu ambiente habitual. Com isso a criança que já se encontra bastante fragilizada pela doença, precisa encontrar meios para externar seus sentimentos, de forma a minimizar seus medos e angústias (SOSSELA; SAGER, 2017).

Com o intuito de minimizar tanto a dor física quanto as angústias geradas pela internação, os profissionais da saúde devem estar atentos à criança. Esta tende a referir sentimentos como solidão, medo da perda ou distanciamento dos pais, medo de achar que não vai poder voltar para casa, insegurança em relação aos seus brinquedos e amigos. Na maioria das vezes, a forma de olhar, de tocar e de falar com a criança, aliados aos procedimentos médicos necessários ao cuidado, são elementos essenciais ao restabelecimento da saúde. É necessário ao profissional de saúde a integração entre sensibilidade e competência técnica (CALVETTI; SILVA; GAUER, 2008).

O presente artigo teve como objetivo conhecer e descrever a visão da criança em idade escolar sobre o processo de internação na UTIP.

\section{METODOLOGIA}

A pesquisa de natureza descritiva e exploratória de cunho qualitativo foi realizada nas unidades de internação, clínica e cirúrgica após a criança ter recebido alta da UTIP de um Hospital Universitário de uma cidade no Sul do Brasil. 
Participaram da pesquisa sete pacientes de ambos os sexos, com idade escolar entre 07 e 12 anos completos, que permaneceram internados por no mínimo 24 horas e no máximo 05 dias na UTIP e que se encontravam internados nas enfermarias clínica e/ou cirúrgica entre 24 horas no mínimo a 05 dias no máximo no dia da entrevista. Foram excluídos os pacientes que permaneceram sob efeito de sedativos após a alta da UTIP, pacientes com sequelas neurológicas prévias ou decorrentes da internação na UTIP, pacientes que não apresentassem condições físicas e mentais para responder aos instrumentos de coletas de dados. A amostra foi intencional e o número de participantes ocorreu por saturação teórica.

Durante o período de coleta de dados, compreendido entre julho e dezembro de 2017, nove crianças preencheram os critérios de inclusão do estudo. Destas, apenas sete concordaram em participar da pesquisa.

Os dados foram coletados por meio de uma entrevista com roteiro semiestruturado. $O$ roteiro versou sobre os motivos da internação e sobre o que a criança entendia de uma UTIP. Somente o pesquisador e a pessoa responsável pela criança permaneceram durante a abordagem, entretanto o responsável foi orientado a não falar com a criança e nem tecer nenhum comentário sobre as respostas dadas. $A$ entrevista aconteceu em uma sala reservada, num período que não alterasse os procedimentos hospitalares.

Para manter o anonimato, as crianças que participaram da pesquisa receberam codinome de cores. Após a fase de coleta de dados, foi realizado o processamento dos mesmos utilizando-se a análise de conteúdo temática de Bardin (2011). As entrevistas foram registradas em gravador de voz e posteriormente transcritas na íntegra.

Por se tratar de uma pesquisa que envolve seres humanos, foram obedecidos os critérios exigidos na Resolução 466/12 do Conselho Nacional de Saúde. A realização das entrevistas somente foi realizada após a aprovação do projeto pelo Comitê de Ética em Pesquisa da Universidade do Vale do Itajaí (UNIVALI) sob parecer número 2.118.123.

\section{RESULTADOS E DISCUSSÃO}

As principais características dos participantes da pesquisa encontram-se na Tabela 1.

Tabela 1 - Caracterização dos sujeitos da pesquisa.

\begin{tabular}{llllll}
\hline CODINOME & IDADE & SEXO & $\begin{array}{l}\text { TEMPO DE } \\
\text { INTERNAÇÃO } \\
\text { NA UTIP }\end{array}$ & $\begin{array}{l}\text { MOTIVO } \\
\text { INTERNAÇÃO } \\
\text { NA UTIP }\end{array}$ & $\begin{array}{l}\text { ENTREVISTA } \\
\text { REALIZADA } \\
\text { APÓS A ALTA } \\
\text { DA UTIP }\end{array}$ \\
\hline LILÁS & $9 a 1 \mathrm{~m}$ & Feminino & 04 dias & $\begin{array}{l}\text { Cetoacidose } \\
\text { Diabética }\end{array}$ & 01 dia \\
& & & & &
\end{tabular}




\begin{tabular}{|c|c|c|c|c|c|}
\hline ROSA & $8 a 4 m$ & Feminino & 02 dias & $\begin{array}{l}\text { Trauma } \\
\text { Abdominal } \\
\text { Fechado }\end{array}$ & 02 dias \\
\hline VERMELHO & $11 \mathrm{a} 3 \mathrm{~m}$ & Masculino & 03 dias & $\begin{array}{l}\text { Trauma } \\
\text { Abdominal } \\
\text { Fechado }\end{array}$ & 03 dias \\
\hline AMARELO & $12 \mathrm{a} 2 \mathrm{~m}$ & Masculino & 01 dia & $\begin{array}{l}\text { Asma } \\
\text { Insuficiência } \\
\text { Respiratória } \\
\text { Aguda }\end{array}$ & 02 dias \\
\hline VERDE & $10 \mathrm{a} 2 \mathrm{~m}$ & Feminino & 01 dia & Crise Convulsiva & 01 dia \\
\hline AZUL & $11 \mathrm{a} 2 \mathrm{~m}$ & Masculino & 02 dias & $\begin{array}{l}\text { Pós-operatório } \\
\text { de Decorticação } \\
\text { Pulmonar }\end{array}$ & 02 dias \\
\hline $\begin{array}{l}\text { VERDE- } \\
\text { ÁGUA }\end{array}$ & $10 \mathrm{a} 11 \mathrm{~m}$ & Feminino & 02 dias & $\begin{array}{l}\text { Pós-operatório } \\
\text { de Laparotomia } \\
\text { e } \\
\text { Hemicolectomia } \\
\text { direita }\end{array}$ & 02 dias \\
\hline
\end{tabular}

Fonte: Os autores.

As categorias analisadas foram construídas após a análise do material colhido nas entrevistas, levando em consideração a orientação teórica e os objetivos da pesquisa. Emergiram as seguintes categorias de análise: o conhecimento sobre o motivo de estar no hospital e o conhecimento sobre o estar internado na UTI.

\subsection{Conhecimento sobre o motivo de estar no hospital}

Conseguir entender o porquê da necessidade de uma internação hospitalar não é uma tarefa fácil nem para os adultos, imagine para uma criança. Na maioria das vezes, estas não concebem a verdadeira gravidade de sua doença e não entendem o tipo de tratamento a que estão sendo submetidas.

A criança entrevistada deveria contar o que sabia sobre sua causa de internação e os motivos que a trouxeram para o hospital e UTI.

Ao ser questionada sobre sua doença, ou seja, a motivação de sua vinda ao hospital, a percepção da criança acerca de saúde e doença muitas vezes surpreende, pois espera-se respostas confusas e desconexas e elas conseguem se expressar de forma clara e objetiva. 
"Porque me deu a crise de convulsão e eu estava com uma dor de perna". (Verde)

"Não sei". (Lilás)

"Porque eu ando de moto, e daí eu fui andar de moto com o meu pai e daí eu bati, eu caí. Eu caí numa velocidade meio rápida, daí eu achei que não era nada. Depois de uma semaninha dessa batida, eu fui pra casa, daí botei salonpas que é um remédio pra tirar a dor muscular, porque eu pensei que era uma dor muscular, daí passou. Depois de uma semaninha, duas semaninhas, voltou a dor e daí passou assim, foi passando, daí, foi aumentando a dor, de 10 ficou a 100 assim a dor". (Azul)

"Porque eu caí de bicicleta". (Vermelho)

"Porque eu estava com falta de ar e a narina não funcionava". (Amarelo)

"Sim. Porque eu fui roubar amora do vizinho [risos] aí eu caí da janela porque o vento levou a árvore”. (Rosa)

"Porque eu estava com apendicite". (Verde-água)

Pelas respostas acima descritas, percebe-se que apenas uma das crianças citadas relatou o nome da doença que motivou sua vinda ao hospital, os outros acabaram descrevendo como causas da internação uma situação vivida por elas.

É possível observar que a criança não faz rodeios, explica sucintamente o motivo de sua internação, é racional e direta. Sua resposta pode ter sido influenciada pelo que seus pais ou outras pessoas que teve contato durante a internação disseram, mas ela tira suas próprias conclusões, formula seu diagnóstico e justifica sua internação.

O momento da admissão no hospital é vivenciado pelas crianças por meio de sentimentos de ansiedade. Com isso, verifica-se a necessidade de desenvolver ações integradas entre profissionais de saúde, família e criança a fim de evitar situações estressoras e impedir que a criança relacione sua doença a sentimentos de tristeza e medo em relação à hospitalização e aos tratamentos realizados pela equipe de saúde (AZEVÊDO; LANÇONI JÚNIOR; CREPALDI, 2017).

A unidade hospitalar é uma instituição de difícil entendimento para as crianças. Muitas vezes é um lugar para o qual vão as crianças que não obedecem a seus pais, por exemplo. Quantas vezes a mãe já ameaçou a criança em seus momentos de desobediência que ele ficaria internado no hospital sozinho? Ou que merecia uma injeção? Estas atitudes dos responsáveis podem gerar traumas nas crianças que serão muito difíceis de serem desfeitos quando houver a real necessidade de uma internação. A internação hospitalar, em muitos momentos, pode se tornar um mal necessário quando se apresenta como o único recurso para a recuperação da saúde da criança.

O ambiente hospitalar é sentido pela criança como um ambiente hostil, novo e desconhecido. A criança percebe que há alguma coisa diferente ocorrendo, procura 
entender o que é, mas nada lhe é informado. Neste momento, cabe aos pais se informarem com o médico assistente da criança e passarem todas as informações necessárias aos filhos sobre: a doença, os exames, a alimentação que passarão a ter, as roupas que deverão usar, os horários que deverão seguir e as pessoas que cuidarão de sua saúde: médicos, enfermeiras, técnicas e auxiliares. Ao omitir a verdade, não esclarecendo determinados procedimentos que serão realizados, com o intuito de proteger as crianças, corre-se o risco de, pelo contrário, deixar as crianças mais ansiosas, angustiadas e nervosas; dificultando assim, sua recuperação (HENRIQUES; CAÍRES, 2014).

O hospital é planejado primeiramente para tratar a doença. De acordo com essa estrutura, na maioria das vezes, não se leva em consideração as necessidades biopsicossociais do sujeito que ali se encontra. O principal objetivo da instituição hospitalar não é o bem-estar psicológico do paciente, mas sim prestar socorro àquele que tem um sofrimento relacionado com o biológico e o orgânico.

Para a criança, estar internada significa distanciar-se de sua vida, seus brinquedos, seus familiares, sua rotina. Independentemente do tempo de permanência no hospital e da faixa etária da criança, a internação hospitalar é uma experiência desagradável, já que esta situação repercute diretamente no seu desenvolvimento (MORAIS; COSTA, 2009).

A criança nem sempre consegue entender o que está acontecendo com seu corpo, e quando adoece, muitas vezes pela fragilidade que esta doença impõe, tornase ainda mais vulnerável.

A internação hospitalar é um evento estressante e traumatizante para a criança, pois ocorre ruptura com o seu meio social, suas atividades, seus hábitos e costumes. Durante a hospitalização, as crianças ficam imersas em um ambiente novo, repleto de restrições e rotinas, com pessoas desconhecidas e, além disso, são submetidas a procedimentos geradores de medo e dor (SANTOS et al., 2016).

O processo de hospitalização pode ser amenizado pelo fornecimento de algumas condições que podem auxiliar a aceitação e a adaptação da criança ao ambiente hospitalar, como por exemplo, a presença dos familiares, a disponibilidade afetiva dos trabalhadores da saúde, a informação detalhada sobre todos os procedimentos que serão realizados e a promoção de atividades que possam distrair e entreter a criança (SILVA et al., 2011).

O método clínico e do desenvolvimento cognitivo, propostos por Jean Piaget, têm amparado grande parte dos estudos referentes à verificação da compreensão da criança sobre o funcionamento de seu organismo, definição de saúde e doença e o entendimento de eventos como a hospitalização. O método clínico foi desenvolvido com o objetivo de entender como as crianças pensam, atuam, compreendem e sentem o ambiente no qual estão inseridas e baseia-se na hipótese de que as crianças possuem 
uma estrutura de pensamento coerente, de acordo com sua fase de desenvolvimento (DELVAL, 2002; MENEZES, 2010).

As crianças entrevistadas encontravam-se na faixa etária dos 7 aos 12 anos, estando compreendidas no estágio operatório-concreto. Neste estágio, a criança já adquire uma melhor diferenciação entre o que é realidade e o que é fantasia. As causas das doenças começam a fazer sentido para a criança e a percepção de que suas atitudes podem melhorar o seu sofrimento e até propiciar a cura da doença também surge nesta fase (BARROS, 2003).

Crianças em idade escolar não apenas compreendem informações concretas, elas também têm capacidade de elaborar pensamentos abstratos e, com isso, conseguem entender a respeito de sua doença e seu tratamento, conhecem a si próprias e possuem entendimento suficiente para perceber quando algo está fora do normal. A partir deste conhecimento, é de extrema importância que a equipe de saúde converse com as crianças, explique, instrua, considere suas queixas e utilizem-nas como orientadoras do cuidado durante a internação e realização dos procedimentos invasivos (SANTOS et al., 2016).

\subsection{Conhecimento sobre o estar internado na UTIP}

A Unidade de Terapia Intensiva Pediátrica é uma unidade do hospital com equipe especializada e suporte avançado para atendimento das crianças que necessitam cuidados intensivos. É um ambiente complexo e de difícil compreensão para as crianças em geral. Ficar na UTIP significa primeiramente medo do desconhecido, medo do que pode acontecer e, principalmente, medo de ficar longe de seus pais que representam segurança para a criança.

A criança entrevistada foi questionada sobre seu conhecimento sobre a UTIP e as respostas demonstram o que a criança sabia ou já tinha ouvido falar sobre a UTIP.

\footnotetext{
"Acho que é um lugar que fica pessoas que estão mais doentes do que as que estão aqui [referindo-se à enfermaria]". (Verde-água)

"Não sei o que é". (Verde)

"Hummm, não sei." (Lilás)

"Não sei". (Vermelho)

"Todo mundo acha que é um lugar que as pessoas que fizeram alguma coisa grave vão fazer, é, vão ficar lá porque a pessoa tá muito ruim, muito ruim, mas não: é uma, é um lugar para as pessoas melhorar da cirurgia que fez e ela é com risco, para não, para não ficar pior alguma coisa assim, só para ficar em observação. Se a pessoa piorar, a pessoa fica mais tempo lá, e lá é assim mais atencioso as pessoas, pois depois que a pessoa fez cirurgia, algumas pessoas vão e algumas não". (Azul)

"É um quarto que todas as crianças e bebês ficam". (Rosa)
} 
"Porque eu tava passando mal, é, não estava passando tão mal assim, mas quando está passando mal a pessoa vai para a UTI”. (Amarelo)

Os participantes relacionam o conhecimento sobre o estar internado na UTIP com a gravidade da doença. Não sabem explicar ao certo como diferenciar um quadro grave e com indicação de UTIP dos menos graves, mas conseguem compreender que apenas os casos graves são os que ficam internados na UTIP.

Pelas falas dos participantes é possível perceber também que, apesar das crianças saberem qual o nível de gravidade que encaminha os pacientes para a UTIP, eles conseguem avaliar que não estavam tão graves assim, mas também foram para a UTIP apenas por precaução ou para que tivessem maiores cuidados e evitasse uma piora de seu estado.

Alguns entrevistados não sabiam o que era a UTIP, ou apenas referiram nunca ter ouvido falar sobre isso antes da sua internação naquele setor do hospital.

Na maioria das vezes, a criança simplesmente é levada para a UTIP sem que seja ao menos explicado o motivo desta internação, o que vai acontecer com ela e o motivo pelo qual os pais não possam permanecer com ela durante todo o tempo. Outras vezes, nem sequer avisam previamente a criança para onde ela está sendo levada, evita-se falar sobre a UTIP com a criança tentando assim minimizar medos e inseguranças. Por tudo isso, muitas crianças não têm conhecimento sobre a UTIP mesmo tendo ficado internadas naquele ambiente, não sabem do que se trata nem para que serve aquela ala do hospital isolada das demais.

Quando questionadas sobre quem falou para elas sobre a UTIP, as crianças entrevistadas referiram, na maioria das vezes, que os próprios pais foram os informantes. Outros referiram já ter ouvido falar previamente sobre a UTIP, mas não especificaram qual a fonte principal da informação.

"Sim. Os meus pais". (Verde)

"Da UTI? Minha mãe falou. Meu pai também". (Verde-água)

"A mãe e o pai". (Vermelho)

“É, uma enfermeira”. (Lilás)

"A minha médica, bem bonita. É igual você, mas a sobrancelha é um pouquinho feia e os dentes assim ó [colocando a mandíbula para frente]". (Rosa)

“Já ouvi falar de UTI algumas vezes”. (Azul)

"Na UTI, não, eu já tinha ouvido falar. Ah, eu escuto nos jornais e ouço das pessoas". (Amarelo) 
No ambiente hospitalar, os profissionais de saúde devem passar informações a respeito de tudo que será realizado de uma forma que tais informações possam ser compreendidas pelas crianças. Uma abordagem compreensível e humanizada, sobre a dor e os procedimentos resultará em confiança e cooperação, auxiliando na conduta do profissional e também na evolução da criança (COSTA; MORAIS, 2017).

O cuidado com a criança hospitalizada exige do profissional de saúde muita sensibilidade além da compreensão da doença, porque é um momento no qual o profissional irá encontrar com uma criança e sua família em situação de vulnerabilidade tanto emocional quanto social e física. É necessário, portanto, incluir a criança no processo de hospitalização, tornando-a um sujeito ativo e valorizando seus desejos, pois elas se comunicam de forma pura e verdadeira (SANTOS et al., 2016).

Dentro de uma Unidade de Terapia Intensiva alarmes sonoros disparam sem cessar, as pessoas se mantêm trabalhando durante 24 horas ininterruptas e procedimentos são realizados a todo o momento. A hospitalização na UTIP na infância, assim como em outras faixas etárias, não é uma situação agradável. A criança é submetida a exames, procedimentos invasivos, seu corpo é invadido por dispositivos que até então ela desconhecia, e com isso ela se sente desprotegida e vulnerável a esse ambiente ameaçador.

As UTIPs possibilitam a sobrevivência e o restabelecimento da saúde de uma pessoa criticamente doente, mas também se configuram em ambientes estressantes, isolamento, ansiedade e hiperestimulação sensorial. A quantidade de aparelhos e alarmes presentes na UTIP a torna um ambiente um tanto assustador para uma criança. São ambientes complexos, que movimentam toda a infraestrutura hospitalar e serviços de apoio, têm rotina própria e diversos estressores - físicos, ambientais, psicológicos e sociais (MORAIS; COSTA, 2009; GEQUELIN et al., 2014).

Os equipamentos e ruídos estranhos que existem no hospital, e que são tão familiares para os profissionais de saúde, podem ser ameaçadores e confusos na visão da criança. É importante que o profissional de saúde esteja atento e avalie os estímulos presentes no ambiente, para que possa proteger a criança desses elementos visuais e auditivos desconhecidos e perturbadores (SANTOS et al., 2014).

A internação hospitalar e principalmente a admissão da criança na UTIP são momentos de muita ansiedade e angústia vividos pela própria criança, pelos pais e familiares. Vários fatores colaboram para isto, sendo os principais o desconhecimento da doença e de sua gravidade, a falta de comunicação entre os profissionais de saúde e os familiares, assim como, o desconhecimento sobre o ambiente e os cuidados na UTIP.

As angústias e medos são exacerbados quando ocorre a internação em Unidade de Tratamento Intensivo (UTI), local no qual a criança fica restrita à cama, sem poder 
se movimentar, está sujeita a inúmeros procedimentos e exposta a materiais e aparelhos que são incomuns para ela (CALVETTI; SILVA; GAUER, 2008).

É importante que os profissionais de saúde que atuam junto à criança na UTIP Pediátrica tenham sensibilidade para adequar suas ações de tal modo que a criança se sinta acolhida e protegida, ao mesmo tempo que está sendo tratada sua doença. Isso fará toda a diferença nas lembranças das crianças após a saída da UTIP e, principalmente, se estas crianças precisarem reinternar na UTIP posteriormente.

\section{CONCLUSÃO}

Com este estudo foi possível perceber que as crianças têm mais conhecimento sobre sua saúde do que se imagina. As crianças sabem muito bem o que está passando com seu corpo, por que estão doentes e também compreendem a necessidade da internação para seu total restabelecimento.

Muitas crianças não sabem o que é UTIP porque ninguém nunca falou sobre esse assunto com elas anteriormente. É preciso não subestimar as crianças e suas necessidades de informação e conhecimento. É de suma importância conversar com a criança e explicar sobre saúde, doença, gravidade e até morte, não apenas no momento de sua internação hospitalar.

Na maioria das vezes, os pais e responsáveis temem que a criança possa não entender ou até se impressionar demais com detalhes sobre sua doença e sua gravidade, têm receio de que ao saber onde estão fiquem mais frágeis e não aceitem tão bem a internação, interferindo em seu tratamento e restabelecimento.

Existem poucas publicações que utilizam a criança como objeto de pesquisa e, portanto, pouco se sabe sobre os conhecimentos que as crianças, nas mais variadas faixas etárias, possuem sobre saúde e doença. Trabalhos realizados dentro do ambiente da UTIP Pediátrica também são escassos, o que justifica aprofundar os estudos neste campo tão pouco explorado. Sugere-se novos estudos que investiguem a percepção das crianças sobre o processo de hospitalização, a internação em Unidade de Terapia Intensiva Pediátrica e que demonstrem maneiras de melhorar a concepção das crianças sobre o entendimento de saúde e doença.

As limitações deste estudo foram o baixo nível de conhecimento das crianças entrevistadas sobre a UTIP, além de sua percepção precária sobre saúde e doença.

A partir deste estudo, percebe-se a necessidade de tornar a criança um sujeito ativo em seu processo de doença e hospitalização, fazê-la participar das decisões terapêuticas para que possa se sentir segura e confortável durante todo o processo de internação.

\section{REFERÊNCIAS}


AZEVÊDO, A. V. S.; LANÇONI JÚNIOR, A. C.; CREPALDI, M. A. Interação equipe de enfermagem, família, e criança hospitalizada: revisão integrativa. Ciênc. saúde coletiva, v. 22, n. 11, p. 3653 - 3666, 2017.

BARDIN, L. Análise de conteúdo. São Paulo: Edições 70, 2011.

BARROS, L. Psicologia Pediátrica: perspectiva desenvolvimentista. 2. ed. Lisboa: Climepsi, 2003.

CALVETTI, P. Ü.; SILVA, L. M.; GAUER, G. J. C. Psicologia da saúde e criança hospitalizada. Psic., São Paulo, v. 9, n. 2, p. 229-234, 2008.

COSTA, T. S.; MORAIS, A. C. Hospitalização Infantil: vivência de crianças a partir de representações gráficas. Rev Enferm UFPE on line, v. 11, supl. 1, p. 358-67, 2017.

COUTINHO, M. O.; LIMA, I. C.; BASTOS, R. A. Terapia do riso como instrumento para o processo de cuidado na ótica dos acadêmicos de enfermagem. ABCS Health Sci., v. 41, n. 3, p. 163-167, 2016.

DELVAL, J. Introdução à prática do método clínico: descobrindo o pensamento das crianças. Porto Alegre: Artmed, 2002.

DOCA, F. N. P.; COSTA JUNIOR, Á. L. Preparação psicológica para admissão hospitalar de crianças: uma breve revisão. Paidéia, v. 17, n. 37, p. 167-179, 2007.

GEQUELIN, J. et al. Percepção de acompanhantes sobre a criança intubada em UTI Pediátrica. Cogitare Enfermagem, v. 19, n. 3, p. 483-490, 2014.

HENRIQUES, D. C.; CAÍRES, F. M. A Criança Hospitalizada: Manual de Orientação aos Pais. Rio de Janeiro: Sociedade Brasileira de Pediatria, 2014. Disponível em: http://www.sbp.com.br/imprensa/detalhe/nid/a-crianca-hospitalizada-manual-deorientacao-aos-pais/ Acesso em: 3 mar. 2018.

MENEZES, M. A criança e sua rede familiar: significações do processo de hospitalização. 2010. 411p. Tese (Doutorado em Psicologia) - Centro de Filosofia e Ciências Humanas, Universidade Federal de Santa Catarina, Florianópolis, 2010.

MORAIS, G. S. N.; COSTA, S. F. G. Experiência existencial de mães de crianças hospitalizadas em Unidade de Terapia Intensiva Pediátrica. Rev Esc Enferm USP. v. 43, n. 3, p. 639-646, 2009.

QUIRINO, D. D.; COLLET, N.; NEVES, A. F. G. B. Hospitalização infantil: concepções da enfermagem acerca da mãe acompanhante. Ver. Gaúcha Enferm., v. 31, n. 2, p. 300-306, 2010.

SANTOS, M. T. N. et al. A relevância da Psicologia no acolhimento da criança em situação de Internação Hospitalar. Ciências humanas e sociais, v. 2, n. 2, p. 149164, 2014.

SANTOS, P. M. et al. Os cuidados de enfermagem na percepção da criança hospitalizada. Rev. Bras. Enferm., v. 69, n. 4, p. 646-53, 2016.

SILVA, F. A. A. A. et al. Estudo Bibliográfico sobre o uso do Brinquedo Terapêutico na Assistência de Enfermagem à Criança Hospitalizada. COORTE - Revista Científica do Hospital Santa Rosa, v. 3, n. 3, p. 33-39, 2011. 
SIMIONI, G. B. et al. A influência do lúdico no processo de hospitalização infantil: a visão do palhaço. Arch. Health Invest., v. 6, n. 1, p. 5-9, 2017.

SOSSELA, C. R.; SAGER, F. A criança e o brinquedo no contexto hospitalar. Rev. SBPH, v. 20, n. 1, p. 17-31, 2017.

XAVIER, D. M. et al. A família revelando-se como um ser de direitos durante a internação hospitalar da criança. Rev. Bras. Enferm., v. 66, n. 6, p. 866-872, 2013. 